\title{
O FEMININO ATRAVÉS DO MITO DA POMBAGIRA E DO MITO DA VIRGEM MARIA EM FEIRA DE SANTANA (1980 - 2002) \\ Indiara Oliveira de Almeida
}

1. Bolsista PIBIC/CNPq, Graduando em Licenciatura em História, Universidade Estadual de Feira de Santana, e-mail: indy.kis22@gmail.com

2. Orientador, Elizete Silva, Departamento de Ciências, História e Filosofia, Universidade Estadual de Feira de Santana, email: cliosilva@yahoo.com.br

PALAVRAS-CHAVE: Pombagira; Virgem Maria, Feira de Santana.

\section{INTRODUÇÃO}

A cidade de Feira de Santana ao longo do século XX vivenciou várias mudanças socioculturais, tornando-se uma referência em saúde, devido as suas árvores e lagoas comuns nos arredores da cidade. Os médicos higienistas do período buscavam recomentar a cidade para os enfermos que não possuíam condições de ir até o Rio de Janeiro. Porém, na segunda metade do século XX, cidade passou por grandes transformações urbanas, ocorrendo entre os anos de1968 a 1985 o processo de industrialização em Feira de Santana, estimulado pela interiorização industrial ocorridas entre 1950 e 1960 que foi estimulado pelo Governo Federal com a inauguração de Brasîlia. (SILVA, 2000.)

A instalação do Centro Industrial Subaé (CIS) no município de Feira de Santana foi criado com a finalidade de complementar as atividades do Centro Industrial Aratu (CIA) localizado em Simões Filho. $\mathrm{O}$ polo industrial da Cidade exerceu um importante papel no desenvolvimento urbano de Feira de Santana, que passou a ser também um entroncamento rodoviário, com importantes rodovias como a Feira-Salvador (BR - 324) e a Rio-Bahia (BR 116) que tinham como objetivo escoar a produção destinada ao consumo nordestino e a passagem de fluxos migratórios do nordeste para o sudeste. (OLIVEIRA, 2008.)

Paralelamente as transformações sócio-urbanas, Feira de Santana também vivenciou um processo de tensões e conflitos no campo religioso, sendo o período em comemoração da festa de Nossa Senhora Sant'Ana, a Padroeira da Cidade, o momento onde os conflitos religiosos eram evidenciados. Nesta festa, havia disputas religiosas onde os representantes da Igreja Católica liderava os cortejos religiosos, sendo acompanhada pela elite feirense, demarcando uma divisão de classe e raça. Paralelamente havia também a presença das Baianas, identificadas como Yalórixás que realizavam os rituais considerados profanos na festa de Sant'Ana. A essas mulheres eram relegadas as últimas posições no cortejo religioso, cabendo a elas respeitar a hierarquia existente na cidade. ( OLIVEIRA, 2016.)

Devido à presença constante das mulheres no campo religioso da cidade, buscamos compreender os discursos relacionados à figura feminina, através dos mitos da Pombagira, um Orixá feminino identificado pela sensualidade e irreverência no Candomblé, e da Virgem Maria, a mãe de Jesus, símbolo de pureza e abnegação feminina no Catolicismo. Esses mitos são utilizados na pesquisa como parâmetros para compreender as mulheres a partir das devoções religiosas em Feira de Santana, no período de 1980 a 2002.

\section{MATERIAL E MÉTODOS OU METODOLOGIA (ou equivalente)}

Tendo em vista que a pesquisa tem como objetivo compreender os mitos da Virgem Maria e da Pombagira como parâmetro para analisar e perceber o processo de manutenção e 
disseminação dos discursos misóginos, machistas e patriarcais existentes na sociedade. Utilizamos o conceito de campo religioso de BOURDIEU (2012), para compreender melhor os processos de disputas existentes no campo religioso da cidade. O mito é outro utilizado na pesquisa, pois de acordo com ELIADE (1998) o mito não pode ser considerado nem uma verdade absoluta e nem mesmo uma mentira, ele um elemento presente das manifestações religiosas ao estabelecer explicações sobre os principais aspectos da vida humana, tornandose portanto uma história Sagrada.

Os mitos da Pombagira e da Virgem Maria são representações de uma crença coletiva que busca definir parâmetros de Mulher, segundo Chartier (1988), as representações são fruto do processo que visa estabelecer uma dominação de um determinado grupo, limitando-o a subordinar-se em meio as relações de poder.

"Gênero é um elemento constitutivo de relações sociais baseado nas diferenças percebidas entre os sexos, e o gênero é uma forma primeira de significar as relações de poder.' (SCOTT, 1989. p.21). A pesquisa também busca compreender as relações de poder existetentes em Feira de Santana, percebendo que o poder pressupõe que algo ou alguém esteja em posição de dominação em relação aos demais, algo que é problemático, pois analisando o campo religioso feirense e suas tensões, é perceptível o processo de dominação da Igreja Católica na cidade com apoio da elite feirense, em contrapartida é notável que no campo religioso feirense quem ocupava os lugares de subalternização eram as religiões Afro-brasileiras, vistas como indesejadas e inferiores ao Catolicismo ou superstições.

O conceito de Raça é relevante, pois o Candomblé tem uma relação muito forte com a identidade negra, sendo a religião fruto do processo de resistência e luta da população negra contra as diferentes formas de opressão ao longo dos séculos. O Terreiro de Candomblé representa um espaço de identidade, pois o fato de ser negro ou mulher não é utilizado como um processo de exclusão de descriminação.

Utilizamos o método da História Oral, que a partir da realização de entrevistas permite apreender aspectos sobre um determinado período. A História Oral permite ao pesquisador perceber diferentes olhares e relatos de uma mesma realidade, mas que se diferenciam devido a subjetividade dos entrevistados. A História Oral possibilitar realizar uma etnografia, a partir das memorias dos entrevistados, nos aproximando do objeto da pesquisa. (GANDON, 2005.) Utilizando o recurso da História Oral, realizamos entrevistas com a Yalórixá Ilda, a Yalórixá Graça, a Irmã Celeste e a Irmã Rosa, podendo presencias singularidades a aproximações em seus discursos. Uma outra fonte utilizada, os exemplares do Jornal Folha do Norte, disponibilizados pelo Museu do Sertão, localizado na Universidade Estadual de Feira de Santana.

\section{RESULTADOS E/OU DISCUSSÃO (ou Análise e discussão dos resultados)}

Apresentação e discussão dos resultados obtidos.

Com base nas pesquisas chegamos aos seguintes resultados.

Os mitos da Virgem Maria e das Pombagiras são muito presentes nas manifestações religiosas em Feira de Santana, sendo comum a realização de festas religiosas em suas homenagens.

Esta pesquisa parte de observações sobre o feminino, na qual a liberdade e a sensualidade estão direta e/ou indiretamente vinculadas através de discursos machistas, paternalistas e sexistas. O que nos leva a questionar o padrão e as normas sociais que subjugam a mulher para que ela represente sempre esse ideal estabelecido pela sociedade. Percebendo-se enquanto um ser caracterizado como passivo e submisso as mulheres reagiram e os aos poucos se organizaram no século XIX com o movimento sufragista nos EUA e na 
Europa, difundindo suas ideias, alcançando grandes proporções, ocasionando desdobramentos até os dias atuais.

Uma das festas mais tradicionais do município era a comemoração da Padroeira da cidade, Nossa Senhora Santana, sendo organizada principalmente pelos Católicos, porem mesmo em meio as festividades cristãs, era comum a presença de outros grupos religiosos que aproveitavam para demonstrar sua fé na padroeira da cidade, identificada com o Orixá feminino Nanã Buruku. ( SILVA, 2016.)

A década de 1980 foi marcada em Feira de Santana pelas tensões envolvendo os adeptos das religiões Afro-Brasileiras e os Católicos, que percebendo o constante crescimento da festa e a presença constante de manifestações Afro-Brasileiras, incentivadas pela Secretaria de Turismo da Cidade, que tinha como objetivo utilizar a festa e as manifestações populares na indústria cultural da cidade, a Igreja Católica buscou restringir a festa e condenar a presença das Baianas, figuras tradicionais na festa de Sant'Ana desde a década de 1940. O receio era que a Igreja Católica perdesse espaço litúrgico e evangelizador na festa, enquanto os cultos Afro-Brasileiros ganhavam cada vez mais espaço, provocando um processo na qual a hierarquia conseguiu no final da década de 80 pôr fim aos grandes Cortejos e ao Bando Anunciador. ( OLIVEIRA, 2016.)

Além das grandes Festas Católicas, a Cidade também possuía outras comemorações, porém restritas ao espaço religioso, como as festas de Pombagira, recorrente entre os adeptos de Candomblé devido a sua irreverência e alegria. É nas festas das Lebaras, termo designando as Pombagiras, que os rituais de proteção são reforçados e os candomblecistas podem se aproximar das entidades celebrando e pedindo por proteção. As festas das Pombagiras são consideradas as mais populares nos Terreiros de Candomblé, reunindo pessoas de terreiros, cidades e credos diferente que se unem para beber e dançar com as Orixás em meio às festividades.

A presença das mulheres no campo religioso de Feira de Santana é majoritária, porém mesmo sendo muito importante no processo de zelar dos rituais, as mulheres exercem diferentes papéis e espaços a depender da religião. O Catolicismo, é mais voltado para a hegemonia masculina mesmo tendo mulheres presentes na organização cotidiana da Igreja, porém são os homens, que estavam hierarquicamente em posição de destaque, que eram prestigiados e estavam em situação de liderança. Paralelamente, no Candomblé, a presença de mulheres exercendo diferentes cargos de prestigio é comum, sendo até mesmo necessária sua presença para a realização de rituais, podendo alcançar o maiores cargos dentro da hierarquia religiosa, a exemplo das Yalórixás.

As Mulheres Candomblecistas e Católicas, mesmo com suas diferenças religiosas, vários aspectos se aproximam, pois no Catolicismo é a Virgem Maria, símbolo de abnegação, pureza e virtude inalcançável, que thes protegem, enquanto que no Candomblé são as Pombagiras, eguns, espíritos dos mortos, irreverentes extremamente sensuais, que realizam esse papel de protege-las, segundo entrevistas feitas com a Irmã Rosa Aparecida em 27/06/2018 e a Yalórixá Graça, em 09/09/2018. Porém mesmo contando com proteções espirituais, de acordo com as entrevistas com a Irmã Celeste 13/05/2018, e a Yalórixá Ilda, em 06/07/2018 essas mulheres ainda permanecem inseridas no meio social, estando sujeitas às opressões dentro e fora de suas casas, sendo vítimas de descriminações por sua cor, seu gênero e também mesmo por sua escolha religiosa.

\section{CONSIDERAÇÕES FINAIS (ou Conclusão)}


Analisamos que a representação da mulher permeia por diversos espaços, a depender da religião, atividade social, classe e raça. Os mitos da Virgem Maria e da Pombagira são representações distintas de um ideal de mulher que está a todo momento em constante transformação, apropriando-se das suas características e as vezes resignificando.

Ser um adepto ao Candomblé e possuir a crença em Pombagira e/ou até mesmo manifestar esta entidade espiritual não significa que a mulher não vivencia as mazelas da sociedade ocasionadas pelo patriarcado e pela misoginia. A crença na Virgem Maria é um elemento que em certos aspectos reforçam os discursos machistas, porém é importante perceber que a apesar da religião ter um papel preponderante da propagação de algumas ideias excludentes e patriarcal, ela não pode ser vista apenas como a culpada desse processo complexo.

\section{REFERÊNCIAS}

BOURDIEU, Pierre. A Economia das Trocas Simbólicas. São Paulo, Editora Perspectiva, 1974.

CHARTIER, Roger. A História Cultural entre práticas e representações. Trad. de Maria Manuela Galhardo. Lisboa: Difusão Editora, 1988, 244 p.

ELIADE, MIRCEA. Mito e realidade. Ed. Pespectiva. São Paulo, 1998. 5 ed.

FOUCAULT, Michel. Microfísica do Poder. $11^{\text {a }}$ ed., Rio de Janeiro: Graal, 1997.

GANDON, Tânia Risério d' Almeida. Etnotexto e Identidade Cultural na Construção da Memoria. Revista da Faeba - Educação e Contemporaneidade. Salvador, v. 14, n. 23, p 227233, jan/jun, 2005.

GEBARA, Ivone. Teologia Ecofeminista: Ensaio para repensar o Conhecimento e Religião. São Paulo: Olho d’Água, 1997.

LAGOS, Nilza de Menezes Lino. "ARREDA HOMEM QUE AÍ VEM MULHER..." Representações de gênero nas manifestações da Pombagira. Universidade Metodista de São Paulo - UMESP. São Bernardo do Campo, 2007.

LANDES, Ruth. A cidade das mulheres. Tradução de Maria Lúcia do Eirado Silva. Rio de Janeiro: Civilização Brasileira, 1976.

MUNANGA, Kabengele. Uma abordagem conceitual das noções de raca, racismo, Identidade e etnia. $3^{\circ}$ Seminário Nacional Relações Raciais e Educação-PENESB-RJ. 2003.

OLIVEIRA, Ana Maria Carvalho dos Santos. Feira de Santana em tempos de modernidade: olhares, imagens e praticas do cotidiano. Recife, 2008.

OLIVEIRA, Josivaldo Pires de. "Adeptos da mandinga": candomblés, curandeiros e repressão policial na Princesa do Sertão (Feira de Santana-BA, 1938-1970), Universidade Estadual de Feira de Santana, Feira de Santana, 2010.

OLIVEIRA, Rennan Pinto de. Sant'Ana dos Olhos d'água: fé e celebração entre a Igreja e o Largo (1920-1987). Feira de Santana, UEFS Editora, 2016.

SILVA, Aldo José Morais. Narutera sã, civilidade e comercio em Feira de Santana: elementos para o estudo da construção de identidade social no interior da Bahia (1833-1937). 2000.

SILVA, Elizete da. O Campo Religioso Feirense: Notícias e Reflexões Preliminares. Sitieenbus (UEFS), Feira de Santana,2009, v. 1

SILVA, Gabriela do Nascimento. Na Terra de Nanã: Candomblés, Territorialidade e Conflito em Feira de Santana (1840-140). Santo Antonio de Jesus, Bahia - 2016.

SENA, Ronaldo de Salles. Feira de Encantados: uma panorâmica afro-brasileira em Feira de Santana: construções simbólicas e ressignificações. Feira de Santana: UEFS Editora, 2014. 